\title{
Kinetic and Electromyography Characteristics Affecting the Performance of the Backhand with One Hand as a basis for design qualitative exercises in Tennis
}

\section{Research Abstract}

This study aims to identify some biomechanical and Electromyography characteristics affecting the performance of one-handed backhand strokes (flat top spin) as a basis for design qualitative exercises in tennis. Researchers utilized the descriptive method involving a device to measure the muscles and analysis Electromyography employing video imaging and analysis of motor skill search using three-dimensional kinetic analysis software. This study was applied on a single IFT-registered Egyptian national team player. The results of the current study indicate that the highest momentum have emerged through the trunk and upper arm in order to produce strong backhand.

The importance of trunk work as it increases force distance transferred to the arm and the stability of the elbow joint and forearm is maintained by the contraction of the biceps and triceps.

The linear momentum of the trunk is more pronounced leftward, and upward trunk movements are essential for generating the necessary linear momentum of the racquet. Moreover, stabilization of the trunk is also considered to be very effective for the sequential transfer of high force and energy through the trunk work. The muscle activity producing movement is the (Deltoid posterior part), and in the muscles against is the (Erector spine muscle). 


\section{1-Introduction}

Kinetics is a science that helps in and influences the scientific progress of motor performances considers studying sports movement through analyzing, clarifying, improving and developing the technique which gives accurate results in motor performance analysis and the identification of errors repositories. The analysis is a way to understand and be aware of sports movement and is studied as an integrated whole. 'This reflects the need by trainers to have a logical analysis of sports skills and access to performance details. Analysis is used in the sports field in order to identify the characteristics of skill technique and for the detection of the defects of performance and comparing it to the theoretical performance curves of the movement and prospects kinetic models.' (Metwaly,A 2008).

Refers (Hassan.Z.M (2004) In order to determine accurately the properties of sports activity, should we get the results through research which applied to high levels of the athletes, and whenever that research applied on the level of sports highest, the results more conform necessary for success in the chosen activity

The record characteristics kinetic and electromyography for higher level players mean use the values indicators and significant by comparing the performances at different levels by measuring the quantitative connotations of mechanical and functional status of the body of the player, either for the whole body or part of its parts.( Eldin.G.A,(1995)

Success in tennis is greatly affected by the technique a player uses. Biomechanics plays an integral role in strokes production. All strokes have a fundamental mechanical structure, and sports injuries primarily have a mechanical cause. (Elliott B., 2006), (Farag.E.w (2007).Backhand strokes are the second most ground strokes performed in games, and are one of the basic strokes in tennis and are accomplished by activating the motor chains for muscular activity, which integrate easily according to the consistency and compatibility of alarming patterns and lower extremities. (Alexandros et al.,( 2010). 
Moreover the force of a tennis stroke depends on the momentum transfer from the racket to the ball during the ball-racket impact. This kinetic striking motion chain opens linkage system from the lower extremities, to the trunk, to the upper extremity, to the hand and then to the racket. The proximal segments accelerate the entire system and sequentially transfer momentum to the distal segment (Lin-Haw Wang,( 2010)..

Some studies (Bahamonde R., 2000) also indicate that the effective transfer of linear and angular momentum from the lower extremity, to the trunk, to the distal upper extremity is very important for an effective tennis backhand stroke. Linear and angular momentum may be described by segmental power transfer. The instant of force generation could represent a part of the contributions of performance in tennis strokes, and is already applied in tennis serve (Reid and Elliott (2002).

During follow-up to researchers to championships Grand Slam, and through the analysis of the distribution of the final strokes in a rally as a function of point winning out come in elite level tennis players, it was revealed that backhand strokes are associated with a greater number of points of winning and poignant, especially when it is a final shot. (Bailey and Mc Garrity,(2012) In local matches the inability of players to perform backhand strokes with high efficiency is noted, which has a negative impact on results. Through their experience in tennis training, the researchers see that this is due to deficiencies in technical requirements that rely on biomechanical and muscular aspects,

Highlighted by (Farag, E, W(2007) In the linear momentum, angular momentum and the force they are effective characteristics of performance backhand, which clearly show during the acceleration phase, where the racquet and hand begins to drop below the ball. And the body effective use of the acceleration and deceleration of the body segments. And the importance of the findings from the study of these types of research, where she was one of the most 
modern trends in the training and assessment and provide the basic instructions for improving and directing the training process to reach the ideal performance. Researchers ' felt the importance of conducting this study as a basis to design qualitative exercise allowed under the guidance of trainers to most exercises similar to the skill in the current study as a scientific attempt to contribute to the achievement of the best motor performance of the backhand strokes.

\section{2- Objective of the study:}

- Identifying some biomechanical variables and some electromyography characteristics affecting the performance of the one-handed backhand strokes in tennis (flat - top spin)

- Define foundations that contribute to put up and design of quality exercises to develop the performance of backhand based on each of the (biomechanical and muscle variables) for the arrival of players to the outstanding performance

\section{3-Research hypotheses}

- There are some biomechanical variables and electromyography characteristics affecting the performance of the one-handed backhand strokes in tennis (flat - top spin)

\section{4-Procedural design}

Researchers utilized the descriptive method involving a device to measure the electric activity of the muscles and analysis electromyography employing video imaging and analysis of motor skill search using three-dimensional kinetic analysis software. This study was applied on a single ITF-registered Egyptian national team player. Table (1) illustrates the sample characterization.

Table (1)

Characterization of Study Sample

\begin{tabular}{|l|l|l|l|l|l|l|l|l|l|l|}
\hline Variable & weight & length & leg & thigh & shank & foot & hand & humerus & forearm & palm \\
\hline Amount & $90 \mathrm{~kg}$ & $181 \mathrm{~cm}$ & $93 \mathrm{~cm}$ & $48 \mathrm{~cm}$ & $45 \mathrm{~cm}$ & $\begin{array}{l}26 \\
\mathrm{~cm}\end{array}$ & $98 \mathrm{~cm}$ & $38 \mathrm{~cm}$ & $31 \mathrm{~cm}$ & $20 \mathrm{~cm}$ \\
\hline
\end{tabular}




\section{5-Programs used in the study procedures}

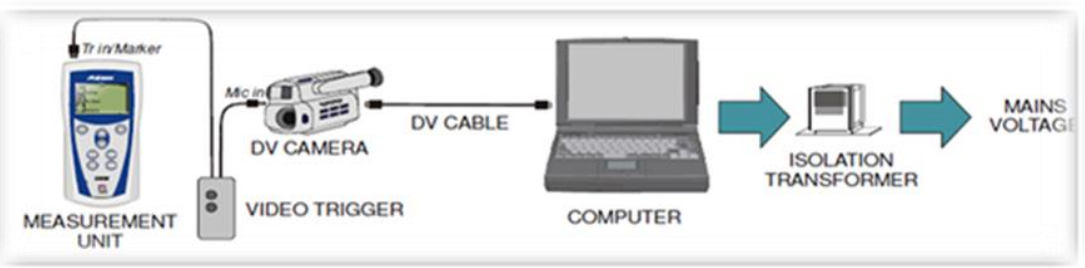

Figure (1)The Synchronization Programs

3D imaging was used through the synchronization program between the kinetic analysis camera (win analyze)and the Mega win 6000 EMG with camera frame rateof 100 frames/s (figure (1).48 surface electrodes have been placed on 16 of the most important working muscles under research after following the steps of theskill anatomical analysis.

The filming location was prepared by positioning ball launcher on either side of the court. Then the drawing scale was prepared and put in the filming scope. Camera No. (1) Was 8 meters away from the playing zone and in the direction of the player. It was 1,47meters high from the ground. Moreover, camera No. (2) Was10meters away, in the direction of the player and 1.47 meters high from the ground.

Player's preparation for imaging: His physical measurements are taken, and then filming-related guide signs are installed on the player's major body joints which are confronting the camera. In addition to that, the electrodes on the muscles surface involved in the performance are installed (E. Paul \& Mark,2011) figure (2). The skill test is explained before the start of filming. A set of attempts were filmed and recorded from among which was chosen the best three of every type to apply the kinetic analysis and electromyography on them.

The researchers applied the procedures for the anatomical analysis. This took place through the phases of the technical performance of the skill and by identifying the most important instants for all the important instantaneous positions. These positions represent the fundamental changes occurring in the movement of each joint working during the performance, at which ends one of the movement phases and begins the next phase. These positions amount to 12 time instants. (E. Paul \& Mark, 2011) also explains that the joints working during the performance are (the right ankle joint) - (the right knee joint) - (the trunk joint) (the right shoulder joint) - (the right elbow joint) and muscular groups participating in the performance of the skill. 


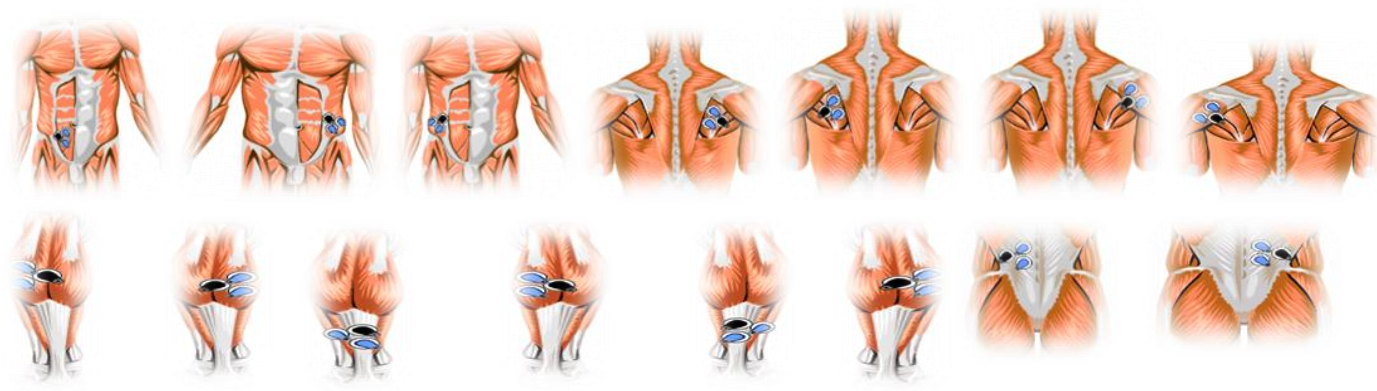

Figure (2).

Muscles Activity during One-Handed Backhand

6-Results

1-The results of biomechanical characteristics

Table (2)

Force and momentum of body joints and COG for flat

\begin{tabular}{|c|c|c|c|c|c|c|c|c|c|c|c|c|c|}
\hline \multicolumn{2}{|c|}{ Skill performance phases } & \multicolumn{4}{|c|}{ Introductory phase } & \multicolumn{4}{|c|}{ Main Phase } & \multicolumn{4}{|c|}{ Final Phase } \\
\hline \multicolumn{2}{|c|}{ Selected time frames } & 1 & 5 & 6 & 7 & 9 & 11 & 13 & 15 & 17 & 18 & 19 & 20 \\
\hline \multicolumn{2}{|c|}{$\begin{array}{l}\text { Time (seconds) } \\
\text { variables }\end{array}$} & 0 & 0.04 & 0.05 & 0.06 & 0.08 & 0.1 & 0.12 & 0.14 & 0.16 & 0.17 & 0.18 & 0.19 \\
\hline \multirow{2}{*}{ right upper arm } & force $(N)$ & 0 & 64.498 & 51.501 & 71.093 & 72.478 & $\mathbf{5 7 . 7 5 5}$ & 121.442 & 99.375 & 76.045 & 143.272 & 80.85 & 52.988 \\
\hline & Momentum (Nms) & 0 & 126.242 & 104.332 & 142.942 & 147.694 & 117.732 & 245.493 & 186.98 & 113.06 & 220.625 & 89.056 & 82.723 \\
\hline \multirow{2}{*}{ right forearm } & force $(N)$ & o & 62.432 & 68.03 & 79.354 & 75.113 & 69.163 & 149.452 & 130.589 & 106.372 & 110.528 & 58.055 & 75.722 \\
\hline & Momentum (Nms) & $\mathbf{0}$ & 121.854 & 129.488 & 151.328 & 146.699 & 135.03 & 282.088 & 229.148 & 119.676 & 183.146 & 111.779 & 150.001 \\
\hline \multirow{2}{*}{ right hand } & force $(N)$ & 0 & $\mathbf{5 0 . 4 3 7}$ & 54.625 & 39.908 & 56.914 & 63.039 & 54.218 & 39.114 & 50.21 & 107.414 & 100.58 & 26.547 \\
\hline & Momentum (Nms) & $\mathbf{0}$ & 81.97 & 89.229 & 77.909 & 104.566 & 122.49 & 84.245 & 61.76 & 25.765 & 198.977 & 183.577 & 48.096 \\
\hline \multirow{2}{*}{ right thigh } & force $(N)$ & 0 & 261.732 & 427.209 & 293.953 & 22.721 & 126.36 & 62.772 & 47.691 & 17.568 & 49.558 & 14.216 & 143.948 \\
\hline & Momentum (Nms) & $\mathbf{0}$ & 267.041 & 527.713 & 356.85 & 35.042 & 211.461 & 108.596 & 84.257 & 31.708 & 62.103 & 20.457 & 178.605 \\
\hline \multirow{2}{*}{ right shank } & force $(N)$ & 0 & 0.706 & 0.681 & 0.775 & 0.818 & 0.526 & 0.248 & 0.124 & 0.103 & 0.117 & 0.134 & 0.165 \\
\hline & Momentum (Nms) & $\mathbf{0}$ & 16.566 & 66.128 & 77.404 & 9.469 & 54.908 & 53.923 & 23.111 & 0.836 & 8.749 & 9.358 & 73.184 \\
\hline \multirow{2}{*}{ right foot } & force $(N)$ & 0 & 3.298 & 2.004 & 2.006 & 1.359 & 0.926 & 1.822 & 2.023 & 0.554 & 2.038 & 0.715 & 0.589 \\
\hline & Momentum (Nms) & $\mathbf{0}$ & 5.690 & 0.643 & 1.995 & 2.103 & 1.692 & 2.202 & 3.219 & 0.369 & 1.980 & 0.373 & 0.725 \\
\hline \multirow{2}{*}{ trunk } & force $(N)$ & o & 637.162 & 143.995 & 452.016 & 435.767 & 612.773 & 598.766 & 535.87 & 469.052 & 743.7 & 853.088 & 210.299 \\
\hline & Momentum (Nms) & $\mathbf{0}$ & 1076.285 & 274.236 & 823.684 & 792.95 & 1218.74 & 834.945 & 935.106 & 805.254 & 1133.973 & 1237.631 & 320.575 \\
\hline \multirow{2}{*}{ body cog } & force $(N)$ & $\mathbf{0}$ & 1380.671 & 748.609 & 506.532 & 826.567 & 925.525 & 1110.444 & 956.02 & 749.559 & 1130.919 & 1125.762 & 264.184 \\
\hline & Momentum (Nms) & o & 89.142 & 72.483 & 69.164 & 80.08 & 48.471 & 67.733 & 74.661 & 63.122 & 51.683 & 78.171 & 80.392 \\
\hline
\end{tabular}

Table (2) illustrates that the largest amount of momentum for the thigh during the introductory phase was (527. 713)NMS and that the largest amount of force in the same phase was (427. 209) While it was in the main phase (211. 461) 
NMS and (126. 36) N.The table also illustrates that the largest amount of the momentum and force of the trunk in the introductory phase is (1076. 285) NMS and (637. 162) $\mathrm{N}$ and in the main phase (1218. 74) NMS and (612.773) $\mathrm{N}$ while the largest amount of momentum of the body's center of gravity path during the introductory phase was (89.14) 2) NMS, while during the main phase it amounted to (80.08) NMS

Table (3)

Force and momentum of body joints and COG for spin

\begin{tabular}{|c|c|c|c|c|c|c|c|c|c|c|c|c|c|}
\hline \multirow{2}{*}{\multicolumn{2}{|c|}{$\begin{array}{c}\begin{array}{c}\text { Skill performance } \\
\text { phases }\end{array} \\
\begin{array}{c}\text { Selected time } \\
\text { frames }\end{array}\end{array}$}} & \multicolumn{4}{|c|}{ Introductory phase } & \multicolumn{4}{|c|}{ Main Phase } & \multicolumn{4}{|c|}{ Final Phase } \\
\hline & & 1 & 5 & 6 & 7 & 9 & 11 & 13 & 15 & 17 & 18 & 19 & 20 \\
\hline \multicolumn{2}{|c|}{$\begin{array}{l}\text { Time(seconds) } \\
\text { I variabtes }\end{array}$} & $\mathbf{0}$ & 0.04 & 0.05 & 0.06 & 0.08 & 0.1 & 0.12 & 0.14 & 0.16 & 0.17 & 0.18 & 0.19 \\
\hline \multirow{2}{*}{$\begin{array}{c}\text { right } \\
\text { uppe } \\
\text { r } \\
\text { arm }\end{array}$} & force $(N)$ & 0 & 136.58 & 58.144 & 44.855 & 33.149 & 121.841 & 249.094 & 131.248 & 149.146 & 161.08 & 55.504 & 23.769 \\
\hline & $\begin{array}{c}\text { Momentu } \\
\text { m (Nm) }\end{array}$ & $\mathbf{0}$ & 173.534 & 46.295 & 54.952 & 35.792 & 170.334 & 355.591 & 164.924 & 224.783 & 239.072 & 51.538 & 33.759 \\
\hline \multirow{2}{*}{$\begin{array}{l}\text { right } \\
\text { forea } \\
\text { rm }\end{array}$} & force $(\mathrm{N})$ & $\mathbf{0}$ & 90.595 & 82.493 & 94.165 & 84.584 & 167.964 & 142.644 & 138.64 & 117.538 & 108.4 & 27.349 & 74.457 \\
\hline & $\begin{array}{l}\text { Momentu } \\
\text { m (Nms) }\end{array}$ & $\mathbf{0}$ & 81.856 & $\mathbf{5 7 . 2 5 7}$ & 64.314 & 38.558 & 211.807 & 186.453 & 135.579 & 176.254 & 140.698 & 28.798 & 110.148 \\
\hline \multirow{2}{*}{$\begin{array}{l}\text { right } \\
\text { hand }\end{array}$} & force $(\mathbf{N})$ & $\mathbf{0}$ & 19.472 & 58.264 & 113.63 & 77.466 & 43.367 & 147.169 & 68.877 & 59.012 & 55.005 & 62.939 & 71.226 \\
\hline & $\begin{array}{l}\text { Momentu } \\
\text { m (Nms) }\end{array}$ & $\mathbf{0}$ & 1.88 & 55.185 & 108.05 & 37.181 & 47.923 & 171.907 & 91.649 & 59.542 & 76.485 & 59.457 & 15.454 \\
\hline \multirow{2}{*}{$\begin{array}{l}\text { right } \\
\text { thigh }\end{array}$} & force $(\mathbf{N})$ & $\mathbf{0}$ & 502.139 & 216.504 & 305.995 & 412.376 & 189.69 & 23.401 & 120.53 & 172.106 & 100.782 & 96.36 & 395.788 \\
\hline & $\begin{array}{l}\text { Momentu } \\
\text { m (Nms) }\end{array}$ & $\mathbf{0}$ & 338.034 & 168.389 & 222.862 & 283.177 & 127.148 & 5.058 & 110.874 & 164.413 & 96.482 & 74.692 & 374.457 \\
\hline \multirow{2}{*}{$\begin{array}{c}\text { right } \\
\text { shan } \\
\mathbf{k}\end{array}$} & force $(\mathbf{N})$ & $\mathbf{0}$ & -0.247 & -0.171 & -0.156 & -0.377 & -0.346 & -0.387 & -0.355 & -0.053 & 0.041 & 0.055 & 0.056 \\
\hline & $\begin{array}{l}\text { Momentu } \\
\text { m (Nms) }\end{array}$ & $\mathbf{0}$ & 16.739 & 9.549 & 12.621 & 23.874 & 9.445 & 7.093 & 21.677 & 25.618 & 11.166 & 2.93 & 3.439 \\
\hline \multirow{2}{*}{$\begin{array}{l}\text { right } \\
\text { foot }\end{array}$} & force $(\mathbf{N})$ & $\mathbf{0}$ & 20.34 & 2.1 & 20.566 & 2.097 & 16.55 & 7.29 & 0.889 & 0.994 & 0.619 & 0.659 & 0.363 \\
\hline & $\begin{array}{l}\text { Momentu } \\
\text { m (Nms) }\end{array}$ & $\mathbf{0}$ & 4.654 & 0.29 & 4.803 & 0.82 & 4.594 & 1.656 & 0.543 & 0.076 & 0.179 & 0.255 & 0.202 \\
\hline \multirow{2}{*}{$\underset{\mathbf{k}}{\operatorname{Trun}}$} & force $(\mathbf{N})$ & $\mathbf{0}$ & 633.919 & 484.391 & 913.29 & 525.441 & 692.56 & 737.684 & 484.311 & 763.642 & 870.984 & 306.415 & 982.877 \\
\hline & $\begin{array}{c}\text { Momentu } \\
\text { m (Nms) }\end{array}$ & $\mathbf{0}$ & 511.747 & 464.237 & $\begin{array}{c}1030.42 \\
8\end{array}$ & 251.408 & 645.641 & 799.197 & 564.965 & 833.514 & 987.572 & 156.674 & $\begin{array}{c}1247.04 \\
9\end{array}$ \\
\hline \multirow{2}{*}{$\begin{array}{c}\text { body } \\
\operatorname{cog}\end{array}$} & force $(\mathbf{N})$ & $\mathbf{0}$ & 1465.639 & $\begin{array}{c}1110.16 \\
8 \\
\end{array}$ & $\begin{array}{c}1059.33 \\
2 \\
\end{array}$ & 926.268 & $\begin{array}{c}1333.58 \\
3 \\
\end{array}$ & 1480.68 & 867.991 & $\begin{array}{c}1476.54 \\
1 \\
\end{array}$ & 1082.49 & 376.916 & $\begin{array}{c}1207.02 \\
7 \\
\end{array}$ \\
\hline & $\begin{array}{l}\text { Momentu } \\
\text { m (Nms) }\end{array}$ & $\mathbf{0}$ & 28.903 & 26.291 & 30.132 & 35.976 & 26.971 & 42.012 & 44.457 & 13.556 & 6.123 & 6.162 & 7.058 \\
\hline
\end{tabular}

The table shows that the curves of the force outcome of the center of gravity links increased (33.149) $\mathrm{N}$ to $(149.146) \mathrm{N}$ clearly with the joints of the striking arm during the main phase, while amounts of total force with the driving leg decreased from (20.34) $\mathrm{N}$ to (2.1) $\mathrm{N}$ during the preparation introductory phase. 
Table (4)

Angles of body joints for flat

\begin{tabular}{|c|c|c|c|c|c|c|c|c|c|c|c|c|}
\hline $\begin{array}{c}\text { Skill } \\
\text { performance }\end{array}$ & \multicolumn{4}{|c|}{ Introductory phase } & \multicolumn{4}{|c|}{ Main Phase } & \multicolumn{4}{|c|}{ Final Phase } \\
\hline $\begin{array}{c}\text { Selected time } \\
\text { frames }\end{array}$ & 1 & 5 & 6 & 7 & 9 & 11 & 13 & 15 & 17 & 18 & 19 & 20 \\
\hline Time (seconds & $\mathbf{0}$ & 0.04 & 0.05 & 0.06 & 0.08 & 0.1 & 0.12 & 0.14 & 0.16 & 0.17 & 0.18 & 0.19 \\
\hline right elbow & 145.221 & 161.368 & 173.613 & 182.122 & 175.975 & 170.949 & 173.262 & 166.403 & 164.423 & 190.011 & 198.621 & 188.7 \\
\hline right shoulder & 47.57 & 40.007 & 39.891 & 39.934 & 41.735 & 44.943 & 41.083 & 45.457 & 46.287 & 56.751 & 56.46 & 65.898 \\
\hline right trunk & 106.025 & 116.89 & 113.844 & 114.024 & 114.067 & 116.947 & 116.15 & 121.738 & 125.03 & 126.433 & 128.635 & 129.238 \\
\hline right knee & 134.196 & 131.279 & 125.753 & 125.094 & 124.027 & 122.873 & 119.645 & 123.005 & 122.343 & 122.054 & 123.164 & 122.143 \\
\hline right foot & 102.368 & 94.242 & 92.065 & 91.116 & 89.215 & 86.774 & 84.476 & 84.231 & 82.716 & 81.97 & 81.968 & 81.254 \\
\hline
\end{tabular}

Table (4) illustrates the importance of that the angle of the knee is between (134.196) and (119.645) degrees and that the angle of the elbow has increased during the beginning of the main phase between (145.221) and (175.975) degrees and that the shoulder angle has amounted to 46.287 degrees at the beginning of the same phase.

Table (5)

Angles of body joints for spin

\begin{tabular}{|c|c|c|c|c|c|c|c|c|c|c|c|c|}
\hline $\begin{array}{c}\text { Skill } \\
\text { performance }\end{array}$ & \multicolumn{4}{|c|}{ Introductory phase } & \multicolumn{4}{|c|}{ Main Phase } & \multicolumn{4}{|c|}{ Final Phase } \\
\hline $\begin{array}{l}\text { Selected time } \\
\text { frames }\end{array}$ & 1 & 5 & 6 & 7 & 9 & 11 & 13 & 15 & 17 & 18 & 19 & 20 \\
\hline $\begin{array}{l}\text { Time-(seconds } \\
\text { Body joints }\end{array}$ & $\mathbf{0}$ & 0.04 & 0.05 & 0.06 & 0.08 & 0.1 & 0.12 & 0.14 & 0.16 & 0.17 & 0.18 & 0.19 \\
\hline right elbow & 148.454 & 172.847 & 161.764 & 165.089 & 169.655 & 159.007 & 163.846 & 148.169 & 166.231 & 190.872 & 168.454 & 169.768 \\
\hline right shoulder & 44.686 & 42.709 & 41.995 & 30.426 & 35.901 & 37.976 & 40.467 & 37.623 & 49.222 & 48.839 & 56.64 & 59.363 \\
\hline right trunk & 125.299 & 127.381 & 129.882 & 138.901 & 138.557 & 138.616 & 141.318 & 145.47 & 157.222 & 158.833 & 159.936 & 160.983 \\
\hline right knee & 128.083 & 133.772 & 136.12 & 141.568 & 143.332 & 143.73 & 145.581 & 148.926 & 151.65 & 152.685 & 153.508 & 154.721 \\
\hline right foot & 83.933 & 92.373 & 93.029 & 92.6 & 93.452 & 89.913 & 90.067 & 91.213 & 92.047 & 92.092 & 91.894 & 91.88 \\
\hline
\end{tabular}

Table (5) shows that the angle of the elbow has increased during the beginning of the main phase reaching (169.655) degrees, and increased more in the beginning of the final phase reaching (190.872) degrees 


\section{2- Results of electromyography Characteristics.}

Table (6)

Activation and Deactivation muscle during motor performance (flat)..

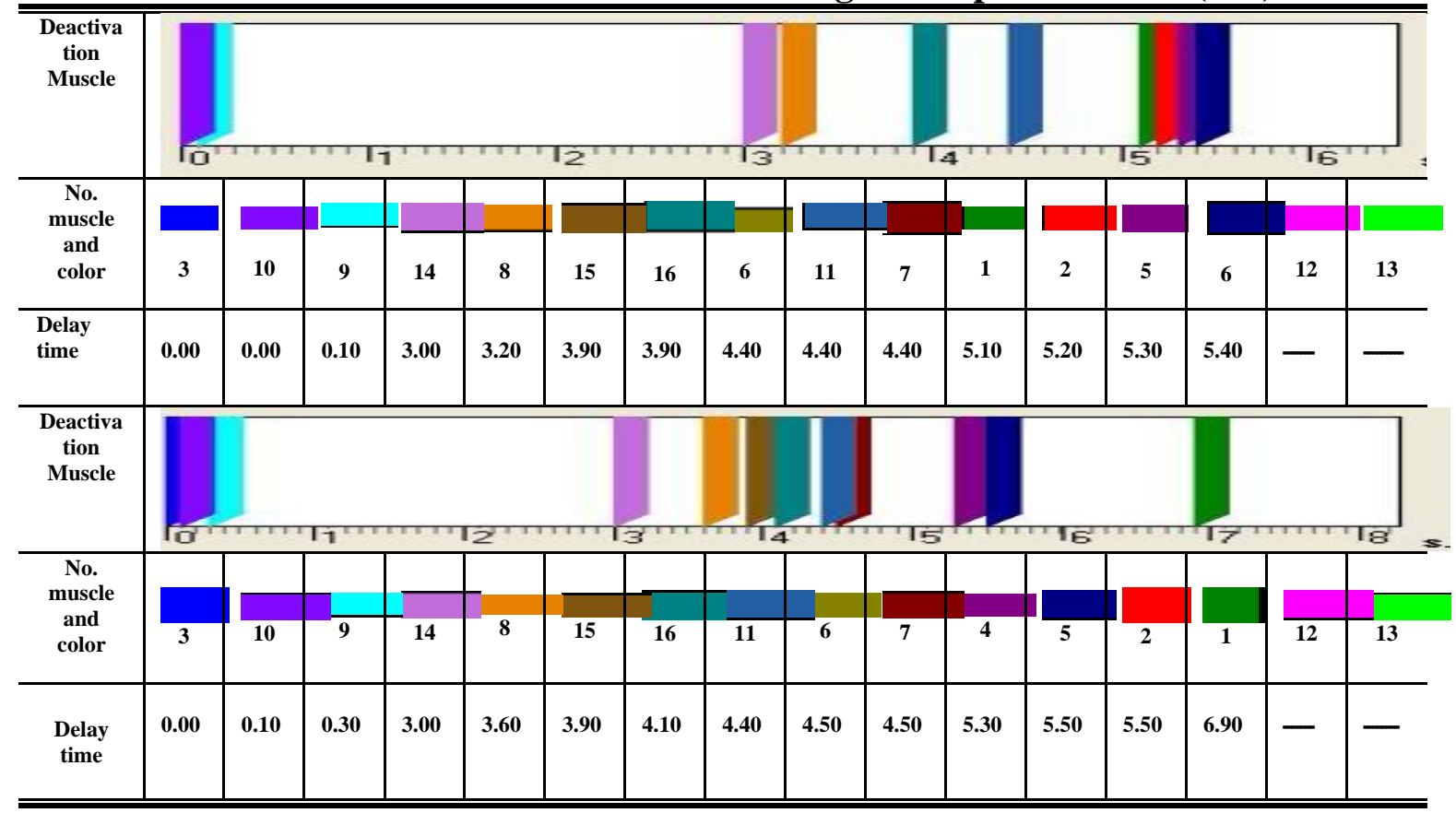

The electrical response of the working muscle began its activity through the following groups (Infraspinatus muscle and Erector spine muscle with time $(00.0 \mathrm{~s})$, followed by electric activity (Deltoid muscle - posterior part)with time (10s), all of which are linked to the lower limb musclesin order to preserve the amount of movement necessary.

Table (7)

Activationand Deactivation muscle during motor performance (top-spin)

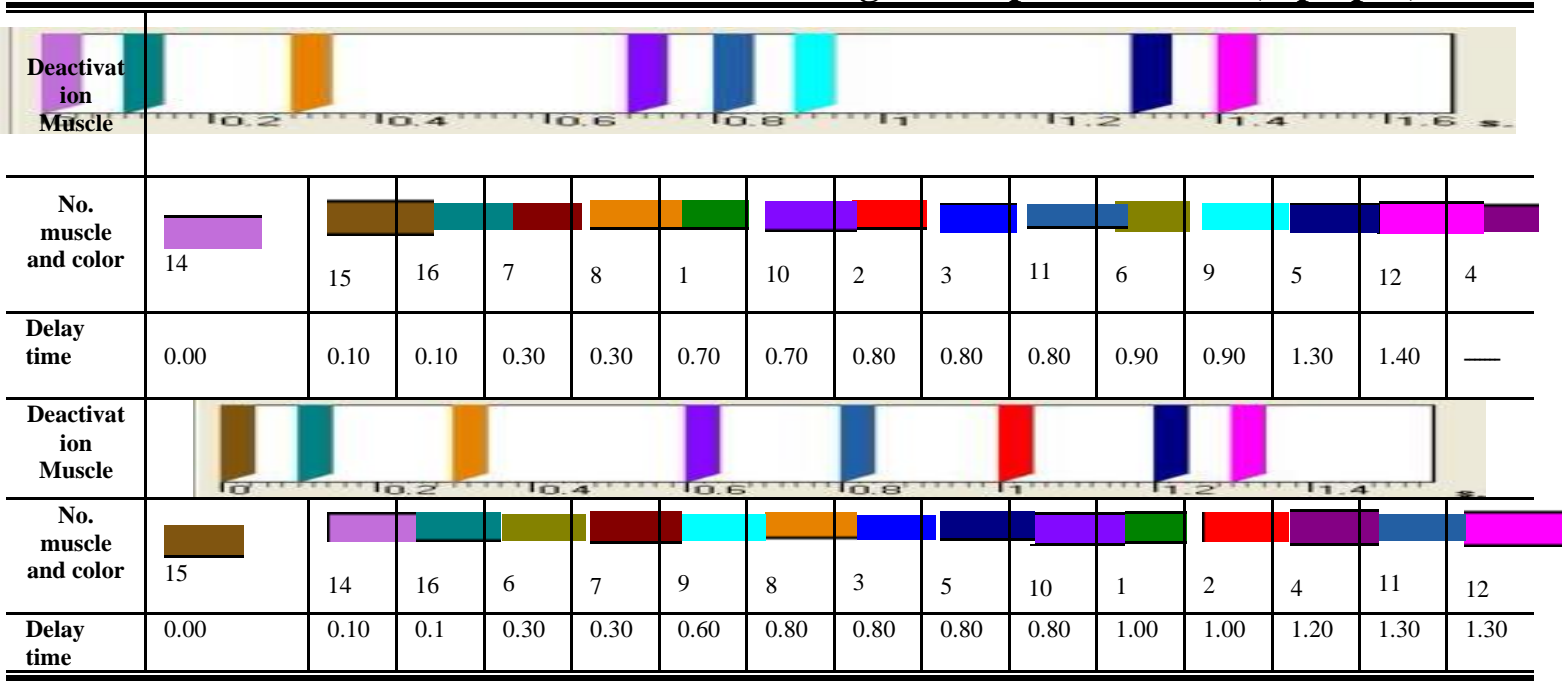

It is clear from table (7)that the following muscle has synchronization of work:the (Gastrocnemius muscle - medial part, Soleus muscle), with time 0.10s.

Figure (3) 
The rate of contribution of the posterior deltoid muscle soleus was big despite its varying proportions while the rest of the contribution rate of the other muscles

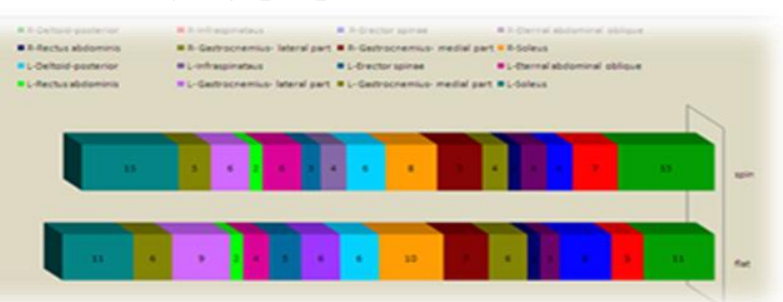
converged demonstrating Consistency and harmony in Performance with the proper streamlining and moves of muscle forces during the performance of skills.

Figure(4): the deltoid muscle is the one with the largest contribution in both flat and topspin where it has the highest amount of electric value reaching (746 uv) and the percentage of its contribution amounted to $15 \%$ where it was the lowest in electric activity reaching (17 uv), while the average electric value is (49 uv)

Table (8) Basic data (EMG)for one handed backhand (Flat)

\begin{tabular}{|c|c|c|c|c|c|c|c|c|c|c|c|c|c|c|c|c|}
\hline ch & 1 & 2 & 3 & 4 & 5 & 6 & 7 & 8 & 9 & 10 & 11 & 12 & 13 & 14 & 15 & 16 \\
\hline $\begin{array}{c}\text { Aver. } \\
\text { Level(UV) }\end{array}$ & 68 & 30 & 50 & 16 & 9 & 39 & 46 & 60 & 35 & 35 & 31 & 24 & 9 & 56 & 39 & 65 \\
\hline SD & 125 & 47 & 29 & 23 & 21 & 48 & 58 & 65 & 53 & 44 & 24 & 16 & 5 & 68 & 38 & 80 \\
\hline MIN(UV) & 3 & 12 & 7 & 6 & 3 & 3 & 6 & 17 & 3 & 2 & 2 & 17 & 6 & 14 & 4 & 11 \\
\hline MAX(UV) & 746 & 343 & 159 & 201 & 175 & 247 & 278 & 276 & 283 & 239 & 139 & 66 & 36 & 537 & 219 & 352 \\
\hline AREA(UVS) & 723 & 311 & 521 & 173 & 98 & 411 & 482 & 639 & 376 & 376 & 331 & 251 & 98 & 586 & 407 & 686 \\
\hline MEDIN(UV) & 23 & 14 & 49 & 10 & 5 & 22 & 26 & 22 & 66 & 19 & 27 & 20 & 7 & 31 & 25 & 27 \\
\hline
\end{tabular}

Table (9) Basic data (EMG)for one handed backhand (Top-spin)

\begin{tabular}{|c|c|c|c|c|c|c|c|c|c|c|c|c|c|c|c|c|}
\hline ch & 1 & 2 & 3 & 4 & 5 & 6 & 7 & 8 & 9 & 10 & 11 & 12 & 13 & 14 & 15 & 16 \\
\hline Aver.Level(UV) & 87 & 38 & 24 & 25 & 14 & 25 & 44 & 49 & 36 & 23 & 20 & 33 & 10 & 36 & 29 & 86 \\
\hline SD & 146 & 53 & 44 & 20 & 20 & 17 & 39 & 48 & 29 & 27 & 38 & 22 & 7 & 54 & 38 & 94 \\
\hline MIN(UV) & 8 & 12 & 5 & 7 & 3 & 3 & 7 & 16 & 7 & 2 & 2 & 16 & 5 & 12 & 3 & 4 \\
\hline MAX(UV) & 955 & 323 & 295 & 99 & 105 & 175 & 215 & 269 & 215 & 143 & 264 & 106 & 49 & 358 & 172 & 332 \\
\hline AREA(UVS) & 532 & 227 & 145 & 149 & 85 & 144 & 254 & 283 & 220 & 134 & 115 & 200 & 61 & 218 & 177 & 525 \\
\hline MEDIN(UV) & 51 & 21 & 10 & 17 & 7 & 19 & 31 & 32 & 30 & 13 & 8 & 24 & 7 & 20 & 12 & 40 \\
\hline
\end{tabular}

\section{7-Discussion}


Results of tables (2) and (3) refer to difference in momentum and amount of force through the phases of motor performance of the backhand stroke in the striking arm joints, the torso, the thigh, the ankle and the foot. This is consistent with (Bahamonde R.,2000)study which indicates that the effective transfer of linear and angular momentum from the lower extremity to the trunk to the distal upper extremity is very important for an effective tennis backhand stroke.

Linear and angular momentum may be described as parts of force and power transfer. Moreover, the instant of power generation could represent a part of the contributions in sports performance, a concept already applied in tennis serve and backhand stroke. The force of a tennis stroke is affected by the velocity of the racquet-head at its impact with the ball through the combinational succession of the flowing force from the feet, legs, trunk and arm to the racquet hand. (Kibler et al., 2004).

Researchers say that the effective role of the legs is indisputable since it represents the $1 \mathrm{BH}$ as a five-phase multisegment stroke involving trunk rotations (hip and shoulder alignments), together with rotation about the shoulder (upper arm), elbow and wrist (Elliott et al., 1978; Reid \&Elliott, 2002; Wang et al., 1998). The strength of a tennis stroke depends on the transfer of the momentum from the racquet to the tennis ball during the contact of the ball with the racquet. As the motor performance is linked to the force of the impact and is always duplicated according to the theory of motor transport and juxtaposition between the striking arm and the driving leg to get a larger amount of force so that the driving force associated with the leg with the force of the striking arm in magnitude and direction.

This shoulder and hip alignment characteristics influence the racquet position at the end of the one-handed backswing, namely an augmented displacement in1BH (Reid and Elliott, 2002).The results of (Fancying et al.,2013) show a significant positive relationship between post-impact ball velocity and the hip and shoulder alignment rotation angles.(Elliott et al., 1995) also points out that the elite players 'mastering of the performance of the backhand stroke 
introductory phase helps them to increase the force of the stroke, and that the racket and shoulder alignment at the end of the backswing may be crucial in the development of trunk rotation. Observations of professional players have shown that many of them prepare for the backhand by positioning the racket parallel to the court fence. This extreme twisting of the trunk could be useful in the development of more angular momentum and thus racket velocity

The results of the current study indicate that the highest momentum have emerged through the trunk and upper arm so as to produce strong backhand stroke. The (Wang et al.,2010) study confirms the more pronounced use of trunk rotation during the acceleration phase of the $1 \mathrm{BH}$ and leads to a larger angular momentum for the trunk and racquet compared with the upper extremity joints. In contrast, (Wang\& et al., 2005) observes that the linear momentum of the trunk is more pronounced in the $1 \mathrm{BH}$. The authors argue that forward, leftward, and upward trunk movements are essential for generating the necessary linear momentum of the racquet.(Elliott\& Christmas, 1995) indicates that the rotation of the trunk and upper arm movement represents about $25 \%$ of the speed of the racquet during the stroke.

Results of tables(3)and (4) show that the angles of the knee.trunk,elbow and shoulder joints have increased significantly during the performance phases, especially at the end of the acceleration phase. Those results are consistent with the results of (Wang, \& et al., 1998) study which indicates that in order to increase ball velocity or control the path of the ball, then spinning the ball is necessary. The shoulder, elbow and wrist joints are involved in the movement of rocketed acceleration at the stroke. The results of the movements of trunk, shoulder, elbow and wrist joints in the acceleration phase is the main movement of the trunk which is bending to the left in order to balance the body and to widen the distance for the forward swing. The main movement of the shoulder joint is abduction for speeding up the racket or accelerating it. The elbow starts to lengthen from the beginning of the acceleration phase and reaches hyper extension immediately after 
impact in order to benefit from the full effect of the principle of extension radius in order to increase speed peripheral which helps to increase the speed of the racquet.

From a functional point of view, racquet velocity in $1 \mathrm{BH}$ is the product of the relative rotational movements of (a) the seven angular velocity components involved with the preparation and (b) the velocity of the center of the shoulder joint that is the result of the angular velocity of the trunk and the velocities of the two hip joints centers, which are determined by the various rotational velocities in the lower extremities,.(Mester, 2006)

Tables (6), (7) describe the muscles that have the largest value of the electrical activity during the performance of the skill in question. These are the muscles of the upper extremity of (Deltoid posterior part): trunk muscles, (Erector spinae muscle, Infraspinatus, External abdominal oblique, Rectus abdominis): muscles of the lower limb (Soleus muscle, Gastrocnemius muscle - medial part, - lateral part). The researchers have referred that to the increasing in the efficiency of sensory receptors in the working muscles.

EMG studies of the elbow and shoulder functions have shown moderate activity of the triceps, middle deltoid, supraspinatus, and infraspinatus muscles during the acceleration phase of the one-handed backhand (Morris et al., 1989). During the backswing phase, all these muscles together with the trunk muscles are extended then this is followed by concentric contractions during the forward swing, thus enhancing the production of force which leads to greater segmental rotations and more velocity.

(Phillip page\&ToddsEllenbeker,2003) add that the working muscles in the acceleration phase which contribute in the push-off of the lower body part and the loading to start the rotation of the thigh are(Gastrocnemius- Soleus-QuadricepsGluteals). The muscles contributing to trunk rotation are the (Oblique- 
Abdominals-back extensors-Erector Spinae). Moreover, those contributing in arm forward swing are the (Infraspinatus- Deltoid- Serratus anteriorTrapezius-Triceps) and the working muscles in the follow-up phase responsible for the trunk rotation are the (Oblique-back extensors-Abdominals). Muscles which are responsible for the arm deceleration are the (Subscapularis (rotator cuff)-Pectorals major-Biceps-Wrist flexors).

Results of tables (6) and (7) show that the electromyography characteristics of each of the activation and deactivation muscle (EMG) of the one-handed backhand strokes confirm that the activity are in the movement-producing muscle of the (Deltoid posterior part), and of the helping muscles which are the (Erector spine muscle) which stabilizes the joints with an almost equal capacity and which plays an important role in the stability of the shoulder joint.(Rio et al.,1988) study indicates that the role of external rotation and abduction in the striking arm during the backhand stroke shows through the high activity of the (middle deltoid, supraspinatus, and infraspinatus)muscles during the acceleration phase. The study also adds that the same muscles are most active during follow-through phase and represents the activity of the (biceps brachial) muscles to try to control elbow extension.

In this regard, both (Andrews \& Escamilla, 2009) confirm that the deltoids muscles provide torque with an estimated contribution of $35-65 \%$ from the middle deltoid, $30 \%$ from the subscapularis, $25 \%$ from the supraspinatus, $10 \%$ from the infraspinatus and $2 \%$ from the anterior deltoid. During abduction, middle deltoid force has been estimated to be $434 \mathrm{~N}$, followed by $323 \mathrm{~N}$ from the anterior deltoid, $283 \mathrm{~N}$ from the subscapular is, $205 \mathrm{~N}$ from the infraspinatus, and $117 \mathrm{~N}$ from the supraspinatus. These forces are generated not only to abduct the shoulder but also to stabilize the joint and neutralize the antagonistic effects of undesirable actions. 
(Kibler WB., 1995) confirms that the deltoid muscle is responsible for moving the scapula through the insertions of three major muscle groups. In addition to that, the Great Latissimus Doris muscle is responsible for internal circulation and the pectoral muscle is not directly linked to the scapula, yet they play an influential role in the implementation of the stroke. In addition to that, the shoulder, the back and the trunk muscles each have a basic role in the stroke. These muscles include the External abdominal oblique and the, Rectus abdomen is, and they contribute to the lateral bending and rotation of the trunk since they are considered as sources of momentum from which results the linear

\section{8-Conclusions:}

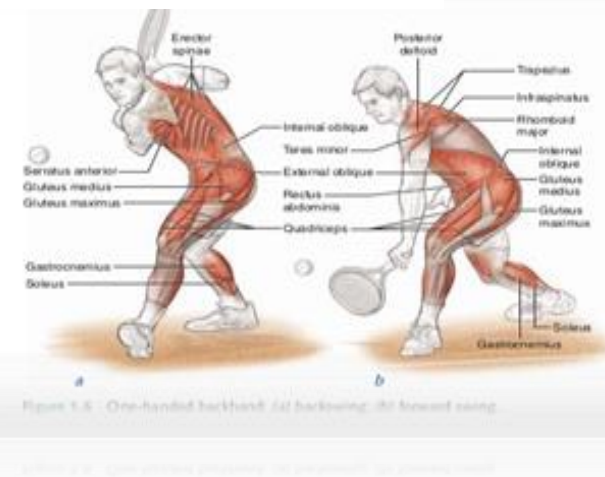

Figure (5) the Anatomy analysis of muscles involved in backhand stroke speed of the arm and the hand at the instant of striking.

The large muscle groups in the trunk and arm at the instant of striking, and the speed of the leg as it is pushing the determines the strength of the stroke. This means that the momentum transfer from one part to another of the body parts leads to the acquirement of the speed required by body parts as the kinesthetic result of result of force exertion. Ground reaction affects distal parts as a result of stabilizing the muscles. This is because the force resultant is produced from the relationship between the muscle and the external strength, that come as a result of the use the largest collection of muscle groups found in the lower part of the body with fast momentum transfer since stopping leads to losing a part of the speed and force gained.

In the acceleration phase, the trunk moves with the racket to increase angular momentum for the preparation of the impact. During this period, the movement of the shoulder is small. When the maximum angular velocities of the shoulder external rotation, elbow flexion and wrist extension occur in the instant 
prior to impact, they then immediately decrease. In this way, the hyperextension of the wrist joint, the cause of tennis elbow, may be prevented. The stability of the elbow joint and forearm is maintained by the contraction of the biceps and triceps

Researchers sees through the findings he must lay the foundations to design qualitative exercises in accordance with the results biomechanics and Electromyography from the study, and applying the foundations are designed qualitative exercise that suit specific physical abilities to performance the backhand stroke, agreement with pointed to it (Bereaa and Alsokary (2010) the need to design qualitative exercise according to the model of the movement used in competition according to the terms of : Proprioception, range of motion, the contractions of muscle groups, dynamic composition (time line of force) during the performance, qualitative exercise should correspond with the skill performance in movement and composition and the requirement in terms of (power-speed) and direction of work on the Biomechanics can contribute significantly to improving the training of the technical performance of the skill.

\section{References:}

1. Alaaddin, Jamal (1994).Lab studies in biomechanicsof sports movements, Al-Ma'arefPublishing House. Cairo. P. 34

2. Alexandros Mavvidis\&AggelosStamboulis,(2010).Differences In Forehand And Backhand Performance In Young Tennis Players. Studies In Physical Culture And Tourism. Vol. 17, No. 4.

3. Bahamonde R. (2000). Changes in angular momentum during the tennis serve. J Sports Sci.; 18 (8):579-92.

4. Bailey \&. Mc Garrity (2012). The Effect of Pressure on Mixed-Strategy Play in Tennis. The Effect of Court Surface on Service Decisions: International Journal of Business and Social Science Vol. 3 No. 20 Special Issue.

5. Craig Tiley (2010). Tennis Australia Player Development Stroke \& Tactical FundamentalsCopyrightTennis Australia. 
6. Elliott B. Review (2006). Biomechanics and tennis.Br J Sports Med; 40:392-396

7. Elliott, B. and Christmass, M. (1995). A comparison of the high and low backspin backhand drives in tennis using different grips: Journal of Sports Sciences 13(2), 141-151.

8. Elliott, B.C, Marsh, T. \& Overhaul., P. (1989). A biomechanical comparison of the multi-segment and single unit topspin forehand drives in tennis: International Journal of Sports Biomechanics. 5:350-364.

9. Fanchiang, H.C., Finch A. and Ariel, G. (2013). Effects of one and twohanded tennis backhands hit with varied power levels on torso rotation. in Book of Abstract, XXXI International Symposium on Biomechanics in Sport, Taipei, Taiwan, July 07-11.

10. Faraj, Ellen Wadih (2007). The new in Tennis, the Road to Championship.Dar Al-Ma'aref Publishing House, Alexandria. P. 90-89.

11. İbrahim CAM et al ;(2013). The Analysis of the Last Shots of the TopLevel Tennis Players in Open Tennis Tournaments; Turkish Journal of Sport and Exercise; -Volume: 15 - Issue: 1 - Pages: 54-57

12. Kibler WB. (1995). Biomechanical Analysis of the Shoulder During Tennis Activities .Clin Sports Med;14(1):79-86.

13. Kibler WB, Sciascia; (2004) . A Kinetic Chain contribution to Elbow Function and Dysfunction in Sports.Clin Sports Med 2004. 23(4):545-52.

14. Mester, J., Yue, Z. and Kleinoeder, H. (2006). Loading in Tennis Stroke Production. In Book of Abstract, Proceedings of XXIV International Symposium on Biomechanics in Sport, Salzburg, Austria, July 14-18. 1-4.

15. Metwaly, Amal Jaber (2008).Principles of Biomechanics and its Applications in the Field of Sports, First Edition, Al-WafaaPublishing and Printing House. Alexandria. P. 25.62.

16. Breaa, M, G ,Alsokary,K,(2010). Basic principles of biomechanics in sport (qualitative analysis) c 2 Alexandria knowledge facility 2010 
17. Morris, M., Jobe, F., Perry. J, et al. (1989). Electromyography Analysis of Elbow Function in Tennis players. American Journal of Sports Medicine, 17(2):241-247.

18. Paul Roetert , Mark S. Kovacs (2013). Tennis Anatomy .United States Tennis Human Kinetics.

19. Phillip Page, Todd S. Ellen Becker (2003). The Scientific and Clinical Application of Elastic Resistance 1st Edition, United State of America.

20. Rafael F. Escamilla, \& James R. Andrews (2009). Shoulder Muscle Activity and Function in Common Shoulder Rehabilitation Exercises: Sports Med 2009; 39 (8): 663-685.

21. Reid, M., Elliott, B. (2002). The one-and two-handed backhands in tennis. Sports Biomech, 2002; 1 (1): 47-68.

22. Ryu, K.N., McCormick, F.W., Jobe, F.W., Moynes, D.R. and Antonell, D.J. (1988). Anelectromyographic analysis of shoulder function in tennis players. American Journal of Sports Medicine. 16,481-485.

23. Wang, L.H, \& et al (1998). Kinematics Of Upper Limb and Trunk in Tennis Players Using Single-Handed Backhand Strokes 16 International Symposium On Biomechanics In Sports (1998).

24. Wang, L.H. and Lin, H.T., (2010). Comparison of Segmental Linear and Angular Momentum Transfers in Two-handed Backhand Stroke Stances for Different Skill level Tennis Players: Journal of Science and Medicine in Sport 13 (2010) 452-459.

25. Wang, L.H. and Lin, H.T. (2005). Momentum transfer of upper extremityin tennis one-handed backhand drive. Journal of Mechanics in Medicine andBiology 5(2), $231-24$. 